\title{
A MEMÓRIA ORGANIZACIONAL COMO DIFERENCIAL COMPETITIVO EM AMBIENTES ORGANIZACIONAIS
}

\author{
Juliana Cardoso dos Santos julimath21@gmail.com \\ Doutoranda em Ciência da Informação pela Universidade Estadual Paulista (Unesp - \\ Marília). Professora do Departamento de Ciência da Informação da Universidade \\ Estadual de Londrina (UEL - Londrina) \\ María Manuela Moro-Cabero moroca@usal.es \\ Doutora em História pela Universidade de Salamanca - Espanha. Professora da \\ Universidade de Salamanca e Universidade Estadual Paulista (Unesp - Marília) \\ Marta Lígia Pomim Valentimvalentim@marilia.unesp.br \\ Doutora em Ciências da Comunicação pela Universidade de São Paulo (USP). \\ Professora da Universidade Estadual Paulista (Unesp - Marília)
}

\section{RESUMO}

Informações direcionadas ao negócio são determinantes para que as organizações gerem diferenciais competitivos. As organizações são compreendidas como sistemas que geram, processam e aplicam informações que, por sua vez, podem ser transformadas em ações estratégicas. Este trabalho tem como objetivo apresentar o referencial teórico sobre o potencial da memória organizacional considerada como um recurso gerador de diferenciais competitivos em ambientes organizacionais, desde que seja estruturada para esse fim. Nessa perspectiva, pretende-se apresentar um ensaio de cunho teórico e de natureza descritiva exploratória enfocando a memória organizacional e sua contribuição para a geração de diferenciais. Como resultado, a partir da análise da literatura, pretende-se evidenciar que a competitividade organizacional está diretamente relacionada aos fazeres organizacionais que, por sua vez, se constituem em distintas memórias individuais e coletivas, cujos processos de apropriação, interpretação e de atribuição de significado são compostos de lembranças e esquecimentos. A memória organizacional pode ser considerada tanto uma fonte de pesquisa quanto uma ferramenta de gestão estratégica, que se relaciona com a capacidade de os sujeitos organizacionais incorporarem saberes. A partir da análise de conceitos e definições pretende-se obter uma visão aprofundada sobre a temática, destacando a memória organizacional como insumo fundamental para a geração de diferenciais competitivos, bem como para propiciar inovação em contextos organizacionais competitivos.

Palavras-Chave: Memória. Memória Organizacional. Competitividade Organizacional.

\section{CONSIDERAÇÕES INICIAIS}

Obter informações direcionadas ao negócio, cujo valor agregado é determinante para a geração de diferenciais competitivos no contexto de organizações que atuam no mercado nacional e internacional é fundamental. Nessa perspectiva, considera-se a informação insumo para todos os processos organizacionais, cujo ciclo informacional advindo desses processos formam a Memória Organizacional (MO).

Evidencia-se na literatura da área de Ciência da Informação (CI) que a memória 


\section{SEMINÁRIO DE PESQUISA EM CIÊNCIAS HUMANAS - SEPECH \\ Humanidades, Estado e desafios didático-científicos \\ Londrina, 27 a 29 de julho de 2016}

é um processo seletivo e interpretativo e ela está relacionada a questões complexas, conforme explica Foster (2011, p.12): “[...] depois de aprender e armazenar novas informações podemos selecionar, interpretar, e integrar uma coisa à outra - para fazer um melhor uso do que aprendemos e lembramos". Sendo assim pode-se inferir que, uma vez que haja a gestão da informação gerada em um determinado contexto organizacional, no intuito de formar a MO, esta última se torna fonte de pesquisa e ferramenta de gestão estratégica, evidenciando-se como fator de produtividade e avanço empresarial em todos os níveis e aspectos organizacionais. Esta ideia é inerente aos modelos normalizados voltados à gestão de documentos e de informação, uma vez que o estudo de contextos organizacionais resulta essencial para aportar um modelo de gestão de documentos que responda as necessidades informacionais da organização e que assegurem o cumprimento legal, governança e a competitividade (INTERNATIONAL STANDARD ORGANISATION, 2011).

Toda organização é capaz de produzir conhecimento, embora somente será eficiente se transformá-lo em estratégias de ação. A esse respeito, Spiller e Pontes (2007, p.99) explicam que "[...] as experiências pelas quais passa uma organização são acumuladas ao longo dos anos, nas suas pessoas, cultura, processos e em seus documentos e esse conjunto de conhecimentos forma a sua memória". Dessa maneira, a MO é construída a partir de uma coletividade, da ação dos sujeitos organizacionais, e pode ser vista como resultado de um contexto social.

Tendo em vista um ambiente de mudança contínua, é necessário estar atento aos aspectos que perpassam a geração, tratamento, mediação, disseminação, apropriação e uso da informação. Nesse contexto, é fundamental estudar o estado da arte do conceito de MO para a geração de diferenciais competitivos.

O presente ensaio tem como objetivo principal apresentar referencial teórico sobre o potencial da MO como um recurso gerador de diferenciais competitivos em ambientes organizacionais, desde que seja estruturada para esse fim. Assim mesmo, pretende-se demostrar como os modelos normalizados de gestão de documentos e de informação têm compreendido essa relação, no que tange ao seguinte aspecto: conhecimento do contexto para gerar informações que propiciem um modelo de MO suficientemente estruturado, no intuito de se obter informações relevantes para a tomada de decisão organizacional.

Pode-se afirmar que o volume dos conteúdos informacionais produzido no contexto organizacional é significativo; não obstante, muito tem sido perdido ou dificultado em relação ao seu acesso e localização. Além disso, atualmente devido a sua produção ocorrer, em geral, em mídias eletrônicas e digitais, fica sujeito a vulnerabilidade de diferentes tipos, no que tange ao seu acesso e uso no médio e longo prazo, evidenciando a falta de estruturação da $\mathrm{MO}$, para o futuro acesso, reutilização e disseminação. Em outros casos evidencia a ausência de uma política sistêmica para a gestão de documentos e informação, bem como a inexistência da uma gestão que contemple a preservação da MO.

\section{PROCEDIMENTOS METODOLÓGICOS}

Este ensaio teórico configura-se como descritivo exploratório, por tentar descrever as características dos fenômenos estudados, estabelecendo relações entre o 


\section{SEMINÁRIO DE PESQUISA EM CIÊNCIAS HUMANAS - SEPECH \\ Humanidades, Estado e desafios didático-científicos \\ Londrina, 27 a 29 de julho de 2016}

potencial da MO considerada como um recurso gerador de diferenciais competitivos para contextos organizacionais.

Segundo Triviños (1987) estudos descritivos exploratórios visam aprofundar o conhecimento sobre determinada realidade; o enfoque se centra em desenvolver uma revisão bibliográfica sobre as temáticas que sustentam a discussão aqui proposta, com o intuito de aprofundar o conhecimento sobre esta temática, com base em um contexto complexo. Este ensaio não finda os esforços em compreender as questões abordadas, mas sim realiza diálogos com base na literatura consultada, almejando reflexões, visando uma melhor compreensão do objeto e dos fenômenos investigados.

\section{MEMÓRIA}

A memória pode ser considerada a história vivida e envolve a articulação entre lembranças (normalmente relacionadas a uma forte emoção como amor, ódio, raiva, etc.) e esquecimentos (aquilo que não se deseja ser, ou que não é entendido como útil); está relacionada a pertencimento, resgate, reflexão, questionamentos, podendo ser considerada um instrumento básico na construção da sociedade e, consequentemente, se torna uma temática complexa que, ora possui teorias discordantes, ora complementares.

Sendo assim, a memória se mostra necessária para que o que foi aprendido persista ao longo do tempo, porquanto se relacionada diretamente a sensação de pertencimento, uma vez que propicia que as pessoas se sintam parte do todo (IZQUIERDO, 2002).

Para Izquierdo (2002, p.9) "[...] memória é a aquisição, a formação, a conservação e a evocação de informações". Muitas vezes o conhecimento permanece sob várias camadas de consciência. A memória contempla também aquilo que nem sabemos que sabemos e, isso, se relaciona com a ideia de articulação. Nessa perspectiva, é possível inferir que aprender é registrar na memória, pois não se pode fazer ou comunicar algo que não se conhece conscientemente.

Memória se refere a aquilo que possa ser recordado, pois os indivíduos passam por diferentes experiências ao longo da vida que, por sua vez, formam diferentes memórias. Assim, cada indivíduo possui suas individualidades e subjetividades, visto que a memória é constituída de lembranças selecionadas, tendo potencial memorialístico a partir de seu registro. O processo da memória tem a haver com a atribuição de sentido a um registro informacional em um determinado contexto, conforme explica Halbwachs (2006): cada memória individual é um ponto de vista sobre a memória coletiva.

Segundo Almeida (2006, p.64) as " [...] organizações são agrupamentos sociais de pessoas e, dado que cada ser humano tem uma memória individual, a organização tem uma memória coletiva, que corresponde, numa simplificação, ao conjunto das memórias individuais" dos sujeitos que constituem determinado ambiente organizacional. Precisamente, trata-se dessa MO e de sua estruturação o cerne deste ensaio teórico.

Segundo Dodebei e Gouveia (2008), os estudos atuais relativos à memória envolvem transdisciplinaridade, uma vez que várias áreas do conhecimento dialogam sobre este assunto. Dodebei (2010, p.71), em seus estudos relativos à memória, 


\section{SEMINÁRIO DE PESQUISA EM CIÊNCIAS HUMANAS - SEPECH \\ Humanidades, Estado e desafios didático-científicos \\ Londrina, 27 a 29 de julho de 2016}

menciona que "[...] é somente a partir do século XX que o mundo é visto como um espaço informacional e memorial, em que os aspectos materiais e imateriais dos objetos criados pelas sociedades entram em disputa". A mesma autora (2010, p.71) relata, ainda, que "[...] a memória compreendida sob a dimensão cultural pode abarcar fronteiras de outras disciplinas que têm o passado como insumo material de estudo, como a História, a Arqueologia, a Ciência da Informação".

Rossi (2010) defende que o discurso a respeito do tema memória é muito antigo e extremamente amplo. Nesse sentido, no contexto da Ciência da Informação (CI) a memória é construída, por meio da interdisciplinaridade, considerada um movimento integrador de saberes, pois requer negociações, esforços e desconstruções, uma vez que o homem é sujeito e objeto de toda Ciência.

A informação se inicia no ato de questionar, e o conhecimento se inicia no ato de aprender intelectualmente com esses interrogantes, pois na MO não basta termos o repositório/arquivo é necessário o repertório/memória, que é a capacidade pessoal e organizacional de estabelecer relações, visto que ela deve enfocar a capacidade de uso e reuso, ou seja, a experiência condensada que alicerça potenciais competitivos. Esse repositório/memória conforma a expressão mais evidente de um modelo sistêmico e sistematizado de gestão de documentos e informação no ambiente organizacional.

A memória é considerada o único meio, pelo qual ideias e palavras podem ser reunidas, fugindo assim ao império do imediato, pois imprime as direções do tempo e propicia uma continuidade social [e, por isso mesmo é atemporal e conquistadora do tempo]. Sem ela, desapareceriam os elos sociais, assim como a própria noção de sociedade, as identidades individuais e coletivas, a possibilidade da construção do conhecimento; ou seja, pode ser considerada essencial para a construção de uma determinada sociedade, assim como para que seja possível a transmissão cultural e de desenvolvimento no tempo (BERGSON, 2011).

Para Huyssen (2000, p.9), "Um dos fenômenos culturais e políticos mais surpreendentes dos anos recentes é a emergência da memória como uma das preocupações culturais e políticas centrais das sociedades ocidentais". Para ele, “[...] a memória se tornou uma preocupação cultural de proporções monumentais [...]" e não há dúvida de que "[...] todos nós representamos os nossos papéis neste processo [...]".

Le Goff $(2003$, p.433) ao afirmar que "[...] o armazenamento de informações permite comunicar através do tempo e do espaço, fornecendo ao homem um processo de marcação, memorização e registro [...]", evidencia que a preservação da memória contribui para o progresso das ciências, tecnologia e da humanidade.

Nesse contexto, o registro, seja em qual formato for [impresso, digital ou eletrônico], possibilita a preservação e o acesso à informação produzida pelo indivíduo no contexto de sua atuação perante a sociedade/comunidade a qual pertence, ademais garanti um modo de atuar, confirmar poder e responsabilidade e de fixar ideias mediante seu conteúdo, permanência e potencial de uso, reuso e disponibilidade; portanto, evidencia-se a importância de abordar a temática MO que se relaciona diretamente com a ação, a gestão e o conhecimento.

\section{MEMÓRIA ORGANIZACIONAL (MO)}

Destaca-se que a MO está relacionada aos processos de gestão de documentos e 


\section{SEMINÁRIO DE PESQUISA EM CIÊNCIAS HUMANAS - SEPECH \\ Humanidades, Estado e desafios didático-científicos \\ Londrina, 27 a 29 de julho de 2016}

informação, enquanto o conhecimento está a seu serviço; além disso, é pragmática e se orienta ao logro de se obter eficiência dos processos organizacionais, no cumprimento de sua função de suporte à inteligência organizacional, em que tanto a informação quanto o conhecimento são reconhecidos como ativos organizacionais, possuindo a partir de sua mediação um valor e potencial competitivo.

A análise da MO interessa as organizações, mais especificamente no que tange a qualidade das ações estratégicas que, por sua vez, são derivadas dessa análise, porquanto geram diferenciais no intuito de promover o desenvolvimento organizacional, com foco na informação como negócio/commodity.

A MO pressupõe um conhecimento gerado ao longo do tempo, e pode ser pensada como um estoque de dados, documentos, informações e conhecimentos, que foram acumulados pelos sujeitos que compõem ou compuseram determinado contexto organizacional ao longo de sua história. Desse modo, quando o indivíduo acessa a MO, ele realiza um ato de interpretação sobre a própria memória individual, podendo contribuir posteriormente para a construção da memória coletiva. Estabelece-se uma relação bidirecional: $\mathrm{MO} /$ indivíduo e indivíduo/MO, bem como ressalta-se a possibilidade de haver relações multidimensionais e/ou dinâmicas: mandatoindivíduo/atividade de negócio e dado-documento-informação-conhecimento/MOtomada de decisão.

No âmbito do contexto organizacional o que cria identidade individual se refere a capacidade de o indivíduo lembrar, e o que é possível construir com base nessas lembranças; assim, as organizações se constituem no sustento de boa parte da vida social do mundo contemporâneo.

Pazin $(2013$, p.922) reforça a ideia anterior ao afirmar que "[...] a memória de uma organização é a representação, ou o conjunto de representações, que o grupo faz do passado dessa organização, a partir dos elementos disponíveis para isso". Precisamente, a natureza, as caraterísticas, o volume, a utilidade e disponibilidade desses elementos são modelados pelos interesses dos produtores, pela existência de políticas de gestão de documentos e de informação, assim como pelas habilidades e competências de seus gestores.

Para que a MO seja útil e tenha potencial competitivo é necessário um ambiente [físico ou não] e ambiência, ou seja, espaços de interferência, favoráveis ao compartilhamento e apropriação da informação e do conhecimento gerados pelos sujeitos que compõem esse contexto organizacional. Desse modo, a MO captura, organiza e dissemina o conhecimento gerado no ambiente, de maneira que o sujeito organizacional, a partir das inter-relações realizadas possa gerar 'novo' conhecimento e inteligência para a organização.

É importante reforçar que a memória pertence aos indivíduos, mas a MO pertence a organização. Dessa maneira, no intuito de potencializar o diferencial competitivo é necessário modelar (estruturar e organizar) os processos vinculados à memória organizacional, orientados a facilitar seu uso e reuso, fator que implica em manter continuamente e ativamente a dinâmica de conversão.

Sendo assim, a MO só tem sentido se realmente for usada, se produzir conteúdo, se mantiver a continuidade de negócio, se puder ser reavivada, ativada, se for uma ferramenta estratégica, se evitar a perda de conhecimento, se explorar experiências, se integrar saberes, se demostrar compromisso, segurança, transparência e cumprimento legal e normativo, em suma se de fato propiciar governança e se constituir em suporte 


\section{SEMINÁRIO DE PESQUISA EM CIÊNCIAS HUMANAS - SEPECH \\ Humanidades, Estado e desafios didático-científicos \\ Londrina, 27 a 29 de julho de 2016}

para a construção de processos de gestão competitivos.

O Quadro 1 apresenta alguns conceitos e definições sobre a $\mathrm{MO}$, mas vale lembrar que no âmbito da Ciência da Informação é um conceito que, ainda, está em processo de consolidação. Nessa perspectiva, destaca-se alguns elementos diferenciais que a completam.

\begin{tabular}{|l|l|}
\hline Conceito/Definição & Autores \\
\hline $\begin{array}{l}\text { (MO) - É o conhecimento de como fazer as coisas, a forma de } \\
\text { abordar os problemas e questões, como tratamos uns aos } \\
\text { outros. }\end{array}$ & $\begin{array}{l}\text { Jackson (2007, p.89) } \\
\text { apud Oliveira (2014, } \\
\text { p.257-258) }\end{array}$ \\
\hline $\begin{array}{l}\text { (MO) - É a aprendizagem armazenada a partir do histórico de } \\
\text { uma organização, e que pode ser utilizada para a tomada de } \\
\text { decisão ou outras finalidades. }\end{array}$ & $\begin{array}{l}\text { Laudon e Laudon } \\
\left(2004, \begin{array}{l}\text { p.325-26) } \\
\text { apud Oliveira (2014, } \\
\text { p.257-258) }\end{array}\right.\end{array}$ \\
\hline $\begin{array}{l}\text { (MO) - Conhecimento corporativo que representa } \\
\text { experiências prévias que são arquivadas e compartilhadas } \\
\text { pelos usuários. [...] constituída por um conhecimento explícito } \\
\text { [...] e conhecimento tácito [...] e abrange aspectos funcionais, } \\
\text { técnicos e sociais de trabalho, o trabalhador e o ambiente de } \\
\text { trabalho. }\end{array}$ & $\begin{array}{l}\text { Lapisa (2007) apud } \\
\text { p.257-258) }\end{array}$ \\
\hline $\begin{array}{l}\text { (MO) - Acervo de informação, conhecimentos e práticas, } \\
\text { agregados e retidos pela organização ao longo de sua } \\
\text { existência, utilizados para o suporte às suas atividades, seus } \\
\text { processos decisórios e para a preservação do seu capital } \\
\text { intelectual, potencializando a gestão do conhecimento. }\end{array}$ & $\begin{array}{l}\text { penezes apud Oliveira } \\
(2014, \text { p.257-258) }\end{array}$ \\
\hline
\end{tabular}

Quadro 1: Conceitos de Memória Organizacional.

Fonte: Adaptado de Oliveira - 2014 - p.257-258.

A partir dos conceitos apresentados no Quadro 1, observa-se que a MO é compreendida como um processo contínuo, que possui sequência lógica e ademais é atitudinal. Como uma rede que, pressupõe relações e inter-relações, composta por equipes multidisciplinares em que o mediador da MO potencializa distintas abordagens, principalmente, no que tange à criação de mecanismos de busca e socialização de informações de maneira ativa ou passiva, estabelecendo processos e coordenando fluxos.

Para Freire et al. (2012) apud Santarém e Vitoriano (2016, p.167)

[...] memória organizacional vai além do repositório, ela se configura numa estrutura de rede, tanto de pessoas, quanto de artefatos, experiências e processos interligados, de modo a configurar uma estrutura de conteúdos e conhecimentos preservados ao longo do tempo que se articulam de acordo com as necessidades organizacionais em diferentes situações.

No âmbito da MO é importante levar em conta múltiplas leituras, porquanto ela é uma ação de autoconhecimento que dialoga com a gestão de documentos, gestão da informação e gestão do conhecimento e, assim, atua tanto no âmbito formal quanto 


\section{SEMINÁRIO DE PESQUISA EM CIÊNCIAS HUMANAS - SEPECH \\ Humanidades, Estado e desafios didático-científicos \\ Londrina, 27 a 29 de julho de 2016}

informal.

A cultura organizacional contribui para uma melhor compreensão das dinâmicas organizacionais conforme explica Pazin (2013): a memória é uma representação do passado, a partir das concepções produzidas pelo grupo, o imbuído de valores, crenças e pressupostos, ritos, rituais e cerimônias, estórias e mitos. É relevante destacar que esta representação do passado trazida ao presente pelo indivíduo ou grupo organizacional, em geral, enfoca a referida representação do passado considerando seu potencial no futuro.

A MO está intimamente relacionada a necessidade informacional e a competência em informação, visto que as pessoas usam a informação para resolver problemas, e o ambiente em que a informação foi gerada determina seu valor e sua importância, pois ao entender a informação de modo subjetivo, é necessário entender os processos sociais e comportamentais da $\mathrm{MO}$, nos quais a informação se estrutura e atua (MENEZES, 2006).

A MO só é eficiente e eficaz quando produz conteúdo, sendo estratégica apenas em determinado contexto ou circunstância [curto, médio ou longo prazo], bem como mantem uma estreita relação com a informação [apoiada em dados e documentos], pois nas organizações o que cria identidade é a capacidade que o indivíduo tem de lembrar ou de consultar suas experiências [explicitadas ou tácitas] e de construir novas ações nelas baseadas.

A compreensão supracitada, confirma o potencial estratégico da $\mathrm{MO}$, pois por meio dela - e do conhecimento tácito e explícito -, é possível responder questões sobre a organização, é possível transformar aprendizagens e oferecer diferencial estratégico para o processo decisório.

Matos (2004) afirma que convém observar e reconhecer que uma MO ativa necessita ser bem gerenciada para estar sempre acessível, desde a fase de origem, isto é, desde o instante em que o documento é gerado, até as etapas decisórias. Nesse intuito, é fundamental aplicar um modelo normalizado que responda ao grau de complexidade que lhe é inerente.

Nessa perspectiva, reafirma-se que a memória organizacional é coletiva, no sentido de que é construída socialmente. Siqueira (2005, p.125) considera a MO um conjunto de procedimentos que possibilitam "[...] localizar, representar, disponibilizar, medir e evoluir os conhecimentos estratégicos da corporação de maneira sistemática e organizada". Molina (2013, p. 48) corrobora com esta ideia, afirmando que a MO "[...] permite que o conhecimento da empresa seja sistematicamente, levantado, tratado, registrado e disseminado, possibilitando sua localização e preservação".

O conhecimento é inerente às pessoas que formam o ambiente organizacional e a MO tem como foco evitar a perda de conhecimento intelectual dos indivíduos que compõem a organização melhorando a comunicação, circulação, integração de diferentes atores visando a aprendizagem contínua, e o compartilhamento de experiências e conhecimentos (tácitos e explícitos) (FREITE et al., 2011).

Infere-se que a MO armazena as experiências vivenciadas na organização, se preocupa com o uso, reuso e compartilhamento do conhecimento, requer análise, e para que seja efetiva deve fazer parte da rotina organizacional, deve ser o objetivo de todos os níveis organizacionais, precisa ser atualizada, estimulada e considerada estratégica, pois a MO está relacionada a questões complexas, a capacidade de análise de experiências e de contextos. 


\section{SEMINÁRIO DE PESQUISA EM CIÊNCIAS HUMANAS - SEPECH \\ Humanidades, Estado e desafios didático-científicos \\ Londrina, 27 a 29 de julho de 2016}

\section{CONSIDERAÇÕES FINAIS}

A partir das reflexões aqui apresentadas com base na literatura analisada, inferese que a temática MO ainda é pouco estudada na área de Ciência da Informação, mesmo sendo evidenciado o potencial competitivo da informação e do conhecimento para as organizações empresariais.

Compreende-se que a memória organizacional emerge do grupo, portanto, parafraseando a Halbwachs (2006) é possível considerar que há tantas memórias quantos grupos existem, sendo a memória por natureza, múltipla e desacelerada, coletiva, plural e individualizada, tendo sentido de continuidade, criando analogias nas organizações em que as pessoas se reconhecem, refletem e tomam decisões. Enfatiza-se que, o descuido da memória organizacional ou sua gestão deficiente pode pôr em risco as estratégias de ação organizacionais, uma vez que a MO gera valores e possui como uma de suas principais funções aumentar a competitividade organizacional.

Compreender a informação e o conhecimento como um recurso estratégico é imprescindível e condição sine qua non à sobrevivência das organizações empresariais. Nessa perspectiva, defende-se que a efetiva construção de conhecimento só ocorre a partir dessa dialogia, entre ordem e desordem, entre construção e desconstrução, pois sem ela não existiria a reflexão, a análise e a crítica, portanto, o pensamento complexo sistematiza e amplia e ao mesmo tempo separa e reconhece o individual e e o coletivo, sendo esta a essencia da MO, a evolução/ação e a interação constante.

Nesse sentido, as organizações devem estar preparadas para lidar com a própria MO de maneira dinâmica, pois a complexidade influi, cada vez mais, no negócio organizacional.

A partir da análise teórica de conceitos e definições ora apresentados é possível obter uma compreensão da MO, evidenciando que a informação e o conhecimento são insumos essenciais para a obtenção da competitividade organizacional.

O trabalho teve como principal objetivo realizar um ensaio teórico sobre o potencial da $\mathrm{MO}$ como um recurso gerador de diferenciais competitivos em ambientes organizacionais, desde que estruturada para esse fim. Desse modo, pode-se considerar que o objetivo previamente proposto foi atingido, acredita-se que este trabalho contribui para o campo da CI, bem como recomenda-se que outros estudos devem ser realizados para o aprofundamento da temática em questão, tão importante para o campo da CI e para as organizações.

A MO é um eterno vir a ser, ou seja, um processo contínuo em que o capital intelectual organizacional pode e deve ser visto como um diferencial competitivo, no qual a informação e o conhecimento se constituem em parte integrante natural da atividade humana.

Por fim, evidencia-se que os seres humanos são inacabados e sendo a informação subjetiva e mediada por relações dialógicas, resulta fundamental a socialização e o compartilhamento de informações e conhecimentos no processo de estruturação da MO.

\section{REFERÊNCIAS}

ALMEIDA, M. B. Um modelo de antologias para representação da memória 


\section{SEMINÁRIO DE PESQUISA EM CIÊNCIAS HUMANAS - SEPECH \\ Humanidades, Estado e desafios didático-científicos \\ Londrina, 27 a 29 de julho de 2016}

organizacional. Belo Horizonte: UFMG, 2006. Tese (Doutorado) - Programa de PósGraduação em Ciência da Informação, Universidade Federal de Minas Gerais (UFMG), Belo Horizonte, 2006.

BERGSON, H. Memória e vida. 2.ed. São Paulo: Martins Fontes, 2011. 184p.

DODEBEI, V. L. D. L. de M. Informação, memória, conhecimento: convergência de campos conceituais. In: ENCONTRO NACIONAL DE PESQUISA EM CIÊNCIA DA INFORMAÇÃO, 10., 2010. Anais... Rio de Janeiro: ANCIB/UFRJ, 2010.

DODEBEI, V. L. D. L. de M.; GOUVEIA, I. Memória do futuro no ciberespaço: entre lembrar e esquecer. DataGramaZero, Rio de Janeiro, v.9, n.5, out. 2008. Disponível em: <http://www.dgz.org.br/out08/Art_02.htm>. Acesso em: 19 nov. 2015.

FREIRE, P. S.; TOSTA, K. C. B. T; HELOU, F. E. A; SILVA, G. G. Memória organizacional e seu papel na gestão do conhecimento. Revista de Ciência da Administração, v.14, n.33, p.41-51, ago. 2011. Disponível em: $<$ https://periodicos.ufsc.br/index.php/adm/article/view/25324>. Acesso em: 19 nov. 2015.

FOSTER, J. K. Memória. Porto Alegre: L\&PM Pocket. 2011. 160p.

HUYSSEN, A. Passados presentes: mídia, política, amnésia. In: . Seduzidos pela memória. Rio de Janeiro: Aeroplano, 2000. p.9-20.

HALBWACHS, M. A memória coletiva. São Paulo: Centauro, 2006.

INTERNATIONAL STANDARD ORGANISATION. ISO 30.300. Information and documentation -- Management systems for records -- Fundamentals and vocabulary. Genève, ISO, 2011.

IZQUIERDO, I. Memória. Porto Alegre: Artmed, 2002.

LE GOFF, J. História e memória. 5.ed. Campinas: UNICAMP Editora, 2003.

MATOS, M. T. N. de B. Memória institucional e gestão universitária no Brasil: o caso da Universidade Federal da Bahia. 2004. 184f. Tese (Doutorado) - Programa PósGraduação em Ciência da Informação - Universidade Federal do Rio de Janeiro (UFRJ), Rio de Janeiro, 2004.

MENEZES, E. M. Estruturação da memória organizacional de uma instituição na iminência de evasão de especialistas: em estudo de caso na COHAB. 2006. $129 \mathrm{f}$. Dissertação (Mestrado) - Curso de Mestrado em Gestão do Conhecimento e Tecnologia da Informação - Universidade Católica de Brasília (UCB), Brasília, 2006. Disponível em: $\quad<$ http://www.bdtd.ucb.br/tede/tde_arquivos/3/TDE-2006-12-19T145234Z362/Publico/Texto\%20Completo.pdf>. Acesso em: 19 nov. 2015. 


\section{SEMINÁRIO DE PESQUISA EM CIÊNCIAS HUMANAS - SEPECH \\ Humanidades, Estado e desafios didático-científicos \\ Londrina, 27 a 29 de julho de 2016}

MOLINA, L. G. Memória organizacional e a constituição de bases de conhecimento. 2013. 199f. Tese (Doutorado) - Programa de Pós-Graduação em Ciência da Informação, Faculdade de Filosofia e Ciências (FFC), Universidade Estadual Paulista (Unesp), Marília, 2013. Disponível em: <http://www.marilia.unesp.br/Home/PosGraduacao/CienciadaInformacao/Dissertacoes/Molina_Leticia_Gorri.pdf $>$. Acesso em: 19 nov. 2015.

OLIVEIRA, S. R de. Memória institucional: lugar de (re)construção de uma memória coletiva. In: SOUTO, L. F. (Org.). Gestão da informação e do conhecimento: práticas e reflexões. Rio de Janeiro: Interciência, 2014. p.255-267.

PAZIN, M. C. C. Centros de memória empresarial: documentos de arquivo como artefatos da cultura organizacional. In: OLIVEIRA, L. M. V.; OLIVEIRA, I. C. B. (Orgs.). Preservação, acesso, difusão: desafios para as instituições arquivísticas no século XXI. Rio de Janeiro: AAB, 2013. p.916-927.

ROSSI, P. O passado, a memória, o esquecimento: seis ensaios da história das ideias. São Paulo: Unesp Editora, 2010. 238p.

SANTARÉM, V.; VITORIANO, M. C. C. P. Gestão da informação, fluxos informacionais e memória organizacional como elementos da inteligência competitiva. Perspectivas em Gestão \& Conhecimento, João Pessoa, v.5, número especial, p.158170, jan. 2016. Disponível em: <http://periodicos.ufpb.br/ojs2/index.php/pgc $>$. Acesso em: 26 jan. 2016.

SIQUEIRA, M. C. Gestão estratégica da informação. Rio de Janeiro: Brasport, 2005. 158p.

SPILLER; A.; PONTES, C. C. C. Memória organizacional e reutilização do conhecimento técnico em uma empresa do setor eletroeletrônico no Brasil. $R B G N$, São Paulo, v.9, n.25, p.96-108, set./dez. 2007.

THIESEN, I. Memória institucional. João Pessoa: UFPB, 2013. 312p.

TRIVIÑOS, A. N. S. Introdução a pesquisa em ciências sociais: a pesquisa qualitativa em educação: o positivismo, a fenomenologia, o marxismo. São Paulo: Atlas, 1987. $175 \mathrm{p}$. 